\title{
Fostering Community and Civic Engagement in Low-Income Multicultural Schools Through Transformative Leadership
}

\author{
Barbara Bader, Judith Horman, Claire Lapointe \\ Université Laval
}

\begin{abstract}
In this study, we examine how transformative leadership enables students from a low-income and multicultural neighbourhood to learn about democracy, responsible citizenship, and community engagement at school. As part of a graduate seminar on critical pedagogy and cultural studies in education, indepth group interviews were conducted with students in three different schools. The objective of the study was to give voice to these students and to better understand how and why they had decided to become involved in a democracyoriented school project. The paper focuses on the results obtained in one of the schools, located in a low-income multicultural neighbourhood, where the students' authentic process of community and civic engagement was facilitated by the transformative leadership of the principal, the assistant principals, and the teacher leaders.
\end{abstract}

In this study, we examine how transformative leadership enables students from a low-income and multicultural neighbourhood to learn about democracy, responsible citizenship, and community engagement at school in accordance with the aims of a program referred to as Démocratie, Citoyenneté et Engagement Communautaire (Democracy, Citizenship and Community Involvement-hereafter referred to as DCEC projects). DCEC projects were launched in 2006 by the Mouvement des Caisses Desjardins (a Québec-based credit union federation), the Centrale des syndicats du Québec (Québec's main teachers' union), and the Fédération des commissions scolaires du Québec (Québec federation of school boards). These projects were also enacted within the network of Établissements verts Brundtland (Brundtland Green Schools) established in Québec in 1993 to promote the values of ecology, peace, solidarity, and democracy.

As part of a graduate seminar on critical pedagogy and cultural studies in education, in-depth group interviews were conducted with students in three schools where DCEC projects had been initiated. The objective was to give voice to these students and to better understand how and why they had decided to become involved in a democracy-oriented school project. This paper focuses on the results obtained in one of the three schools, located in a low-income multicultural neighbourhood, where the students' authentic process of communi- 
ty and civic engagement was facilitated by the transformative leadership of the principal, the assistant principals, and the teacher leaders.

\section{Research Problem}

\section{Conceptual Framework}

The process underlying the DCEC project described in this article is interesting because of a certain number of characteristics that can be tied to critical pedagogy (see Bader, 2010; Freire, 2004; Giroux, 1988, 2004a, 2005; Kellner, 2001; Pouliot, Bader, \& Therriault, 2010) and that underscore the value of a strong link between emergent pedagogy and the civic and community engagement of young people. Critical pedagogy aims at fostering awareness of the social, cultural, economic, and spiritual conditions which shape students' existence and promote their political agency in order that they may become empowered to explore their potential as moral and civic agents, supported by their capacity to transform reality (Giroux, 2004b). Emerging pedagogy refers to a teaching approach wherein students define their learning project and the main stages of its implementation (Bader, 2010).

Henry Giroux's analysis of the North American educational system demonstrated how remote academia and curriculum are from the concerns and preoccupations of young people nowadays, a remoteness which contributes to social conformism, thereby preventing them from engaging in civic and critical democracy. He also stressed the importance of seeing culture and media as forms of pedagogy which shape the way young people define themselves. In his book Teachers as Intellectuals, Giroux (1988) challenged teachers and school leaders to transform learning into significant meaning and has called upon academia to become more relevant and meaningful to all youth. According to Kellner (2001),

\footnotetext{
While culture can be conservative and shape individuals into conforming to dominant modes of thought and behavior, it also presents a site of resistance and struggle. Critical pedagogy and cultural studies thus attempt to give voice to students to articulate their criticisms of the dominant culture and to form their own subcultures, discourses, styles, and cultural forms. (p. 234)
}

For the purpose of this study, two main aspects of critical pedagogy have been retained: to give voice to students in order to better understand how they define their identity and to study how a specific school culture and form of leadership might foster their civic agency, while acknowledging that, most of the time, school cultures tend rather to lead to student disengagement and individualism.

With regard to the role of school leaders in creating inclusive and equitable schools, recent leadership studies have led to the identification of a form of leadership which is rooted in a vision of social justice, equity, and action for emancipation. Principals and other educational leaders who share this vision and endeavour to create authentically inclusive schools are called transformative leaders. According to Shields (2010), "Transformative leadership begins with questions of justice and democracy; it critiques inequitable practices and offers the promise not only of greater individual achievement but of a better life lived in common with others" (p. 559).

Lapointe, Shields, and Langlois (2009) explained that transformative leaders are profoundly aware of and take into account issues of power and privilege, equity and inequity in the wider society. They know that students do not have access to the same material and cultural capital outside of school, and engage in emancipatory leadership practices in order to transform both the culture and the structure of their school. 


\section{Research Context and Questions}

The starting point for DCEC projects consisted of an exploration, by the students, of the resources and living conditions of their neighbourhood. The goal was to enable students to develop a project focused on improving an aspect of life in their community according to a democratic approach and with a view to fostering a more fully informed kind of civic engagement. Accordingly, in this study, the concept of "environment" is viewed as also encompassing the social environment.

Of the three DCEC projects initiated in the Québec City area in 2008, one showed particular interest for the following reasons: it was completely student-initiated, it produced tangible results, and was the only project developed in a low-income multicultural school. Given these characteristics, we wanted to investigate the following questions: (a) How do participating students view themselves, their school, and their neighbourhood? (b) What is their understanding of democratic culture and citizenship? and (c) What is the educational and democratic character of the DCEC project they initiated in this low-income multicultural neighbourhood?

\section{Method}

\section{Participants}

In this paper, we present the results of an analysis of the statements of 7 students (4 boys, 3 girls) from grades 11 and 12 at a Québec City high school (population of between 600 and 700 students). The participating students were enrolled in non-selective music or sports programs and came from low-income and/or multicultural families. They accepted to take part in interviews on a voluntary basis. We also met the educator responsible for supervising and facilitating the DCEC project at this school, a full-time recreation technician in charge of organizing after-school activities. We have included his comments whenever they flesh out or clarify the statements of students.

\section{Data-gathering Process}

Semi-structured 1-hour interviews were conducted in small groups of 2 to 3 students during lunch hour or once classes ended in the afternoon. We also met the educator in charge of supervising the DCEC project during these periods. The interview protocol was structured around three main focuses of investigation: namely, (a) the view that young people have of themselves, their school, and their neighbourhood; (b) their understanding of democratic culture and citizenship; and (c) the educational and democratic character of the DCEC project as defined by the students when describing the sequence of project phases, their motivation towards the project, and their opinion with regard to avenues for improvement. All interviews were tape recorded and transcribed in their entirety.

\section{Analyses}

We performed a thematic analysis of verbatim transcripts (Paillé, 1996). To this end, one member of the team systematically coded statements, basing coding on the ideas expressed and constituting thematic categories according to groupings of the codes thus ascribed. Code groupings were often based on the recurrence of a given expression. Thus, the thematic categories were not predetermined, but instead flowed from the coding process. In 
order to ensure the validity of the analysis, a second member of the research team reviewed the initial coding with the first coder, analyzing together all of the verbatim transcripts until data saturation (i.e., no new themes emerged) occurred.

\section{Results}

The DCEC project that we studied in this school was anchored in the everyday life of young people and was thus located at the intersection of the family, school, and neighbourhood of the participating youths. The project emerged out of the need to respond to an event that threw into question not only the way these young people defined themselves, but also the type of relationship that they maintained toward their school, which they esteemed and appreciated, but which enjoyed no public recognition: "What he (the radio host) said, was that in [name of school], there were fights going on all the time; that's what he meant. I don't like that way of talking" (Student 2 [S2]).

In addition, an analysis of the students' statements suggested that contextual conditions specific to the culture of their school would be conducive to a kind of community and civic engagement offering a certain authenticity for the students. It is these cultural characteristics that we bring out through the presentation of themes that emerged from the analysis of statements: (a) the view that students take of the interrelationships between their school, their neighbourhood, and their family-A neighbourhood school: a discourse on identity; (b) their understanding of democratic culture and citizenship and the view they take of everyday life and the democratic culture at school-A school culture of democratic engagement; and (c) the way in which the DCEC project channelled young people's agency (i.e., capacity to act)-The educational and democratic character of the DCEC project.

\section{A Neighbourhood School: A Discourse on Identity}

Our analysis brought out the importance of a certain kind of identity discourse among students - a discourse that offers a description of the character and specificities of a group of people and highlights what these people are able to accomplish. The students' statements indeed suggested a conception of collective identity framed in terms of social relations rather than of "essentialist" characteristics. For example, one female participant who was enrolled at the school, but who lived in another neighbourhood, stated that she shared the collective identity of the school she attended because she shared her everyday life with the other young people who lived in this neighbourhood:

Even if I live in [name of another neighbourhood], I spend more time at school than I do at home. What's more, I hang out with people from [the neighbourhood in which the school is located] - it's a very very big part of my everyday life, y'know. Like it or not, I hang out in this neighbourhood, even if I wasn't born in it. It's really important. (S4)

For this student, collective identity thus goes hand in hand with the neighbourhood, which she tended to cast in a positive light.

Similarly, the view held by these students respecting the relationships between school, family, and neighbourhood was expressed in terms of social and community ties. Thus, for these students, the school and the neighbourhood formed a "single community," which, along with the family, constituted the spheres of their everyday life. More specifically, the students identified two particularities in connection with their neighbourhood: a concentration of lowincome individuals and a high number of immigrants, who also have low incomes. However, one student pointed out that low income or immigrant status did not necessarily imply low 
schooling levels. Social or systemic conditions may impose constraints with which families must contend. The students noted the difficulties and poverty to be seen in their community. In this context, the role played by the school as a community support contributed significantly to the vitality of the community. Below are a few illustrations of the role of the school, as referred to in the students' statements.

In response to low incomes, the school offered low-cost (or free) activities:

I think people are a bit poorer here; y'know, you can try and hide it, but my feeling is, there are a lot of people who don't have money. And, y'know (at school), there are a lot of things that don't cost anything and that are open to people. That's great. (S3)

In response to substance abuse situations in some families, the school represented a place of stability:

It's really a neighbourhood where, as they say, there's a lot of poverty. There are a lot of people on welfare, a lot of people, um, y'know, kids who come home and, um, there's a big party goin' on, dad with a beer bottle in his hand all day long and all that; just as I'm tellin' it. When the kids come to school, it's like a little break, y'know, like resting on a little cushion for 12 hours. Then you go back home; y'know, it does you good. (S4)

In response to the needs of immigrants, the school offered support services: "There are French-Spanish noontime get-togethers too. It's people who... people who want to learn. I'm often there, just to learn Spanish. And there's people who want, who still have a hard time speaking French" (S3).

The social bonds between this school and its neighbourhood were quite apparent and closely intertwined. The values of sharing and social engagement, identified by the students we interviewed, could be linked to the importance of social ties in this neighbourhood. Furthermore, the aspirations and values expressed by these young people and experienced at school appeared to be rooted in certain family relations:

I grew up in an environment in which my parents went and helped out other people who were suffering $[. .$.$] as a result, there were a lot of people at our house. It's, like, a real safety net so$ that everyone helps one another. (S4)

Conversely, for some students this culture of participation and social engagement in relation to everyday life in the neighbourhood and their family found an echo at school. These students took part in activities that extended beyond the times and spaces of the school setting to the extent that it became difficult to clearly distinguish between the activities associated with the school and activities occurring outside of school. As one example, it is worth noting the humanitarian assistance trip project organized by two teachers, which grew into an assistance project targeted at Columbian youths and organized by members of the neighbourhood community.

All in all, the close ties that the school appeared to maintain with its surrounding community represented a major component of the vitality of everyday life in the neighbourhood and the families who were members of it. By the same token, the school experience of young people was enriched by the ties and the openness of the school toward their neighbourhood. These young people were proud of their school and appreciated the role that it played in their neighbourhood, such that school, family, and neighbourhood stood out as three contexts of everyday life within one and the same community. This is a condition that, in our view, cannot be found in all schools and that perhaps distinguishes a neighbourhood school from a composite high school.

The pride expressed by the students of this school contrasted with a stigmatizing discourse on identity to which they were also witness at the time of our interviews. This 
stigmatizing discourse generated an image of them that did not accord with the view they held of themselves. Just such a discourse was conveyed by the media event that crystallized the aims of the DCEC project of these students. Specifically, a radio host apparently presented the students at the school as belonging to a neighbourhood in which young people regularly engaged in street gang-type activities.

The students we interviewed explained their way of resisting this type of identity discourse in the following terms: "The school [name of school], okay, yeah, some 'crummy' things happen there, but we're not just that" (S4). According to this abusive categorization, their identity was defined on the basis of their belonging to the neighbourhood in which the school was located; conversely, the reputation of the school, as described by the radio host, was purported to contribute to a negative image of the neighbourhood: (on the radio) "They repeated the name of the neighbourhood 25 times. They presented [the name of the school] as being a 'fight' school" (S1).

The inaccuracy of the description, coupled with the accompanying depreciation of their identity, was felt by these students as being unfair: "I feel that's going pretty far. Yeah, it's unfair" (S2). The resulting choice of their DCEC project stemmed from a crystallization surrounding this feeling of unfairness. These students perceived themselves as engaged young people who got involved in order to contribute to other people's happiness - a thing that brought them happiness in return. Consequently, they wanted to build awareness about how they defined themselves.

The statements gathered suggest that the reaction to such stigmatizing identity discourse was all the more strong since, in this neighbourhood, social ties appeared to be closely interwoven between the family, school, and neighbourhood. According to the students, the media discourse had an impact on the confidence exhibited by older people towards youth and on the quality of intergenerational relations. As a result, their project consisted of proposing afternoon group activities (games and songs) to organizations whose work would bring them into contact with three targeted groups among the local populace: children in daycare centres, children in primary school, and elderly people. These activities were held on Thursday, whence the name of their project - initially the "jeux dits bonheur" and subsequently "Jeudi bonheur" (an untranslatable pun in French involving the word for "games" [jeux] and "Thursday" [jeudi]). The next section serves to show how the school culture fostered community and civic engagement, having a certain authenticity for these students.

\section{A School Culture of Democratic Engagement}

We were astonished by the school's culture of participation, which became apparent from the statements of students bearing on (a) the intensive presence of after-school activities, (b) a structure of democratic participation in school life, and (c) the quality of the relationship between young people and adults at the school. This context would appear to foster the enactment of a DCEC project, as we suggest further on.

After-school activities. Whenever the students talked about the school activities in which they were involved, they spoke about them with enthusiasm and pride. These activities represented a space enabling them to experience and express a passion: "Me, at any rate, I really get into it. I love my school and the environment I'm in. Yeah!" (S4). The opportunity for students to get involved in numerous after-school activities appeared to contribute to this culture of participation by structuring their relationship to times and spaces and by filling a function of stimulation. For example, the places that students liked to go to during their spare time at school — at lunch time, for example — were the cafeteria, the park, the after-school ac- 
tivities room (where we conducted the interviews), and the gym were equipped to offer activities in which young people could socialize through games or projects.

The opportunity to actualize a passion and membership in a group appeared as an antidote to apathy. Taking part in an activity is something that imparts dynamism to everyday life. These youths appreciated being surrounded by motivated people. Their involvement appeared to give them the feeling of being useful:

\begin{abstract}
You're sleeping and you think about it; you're not dreaming, you're thinking about it - all the time, all the time. But I love it, 'cuz sitting around for a whole week, just going to school, I wouldn't be able to take it. [...] They (students at the school) have the opportunity to do something with their lives. Y'know, that's really great. Y'know, instead of sitting around in the basement all day long, well, they can do something. So they come to school, but they don't just come to school. They also have fun at school, and that's something that's really important. (S4)
\end{abstract}

It may well be that participation in after-school activities motivated them to come to school, provided them a form of support in the near term, and constituted a source of hope.

It is worth noting that the educator in charge of organizing after-school activities (i.e., the recreation technician) pointed out that the young people who participated in the DCEC project numbered among those who did well in their academic courses and that among the $55 \%$ of students who took part in after-school activities, they were the more intensively engaged. After-school activities were at the core of their everyday lives and contributed to building a culture of participation that we were able to perceive in the democratic culture at this school.

Structure of democratic participation. The statements gathered at this school suggested a form of democratic participation in decision making that is founded on a representative structure which is theoretically part of any school in the province of Québec, but seldom so extensively present. Students indeed participated in the decisions surrounding the development of after-school activities and they also took part in certain decision-making bodies, such as the school governing board. ${ }^{1}$ In addition, the representatives of each orderclassroom, grade, school - assembled in a student council supervised by a recreation technician and a teacher. Both student council presidents (a teenage boy and a teenage girl) sat on the school governing board. The presidents kept the student council informed of the subjects dealt with at the board and made known the views of students. These participation and opinion-voicing structures were supported by information updates broadcasted throughout the school on the student radio.

This structure of democratic participation, put in place by the principal, encouraged students to speak out, either during discussion times specifically set aside for that purpose in classroom groups or at bimonthly meetings of the student council. In classroom groups, opinions were voiced by means of information periods dedicated to the discussions occurring within the student council, opinion surveys, and discussions whose content was reported to the student council:

[name of the group representative] has already done a survey on three or four things: what our class thought about such and such thing. Then she submitted it (to the student council) and after that, they did another survey with what had been accomplished [...]; they take into consideration what we think and what we want before they do it. (S4)

\footnotetext{
${ }^{1}$ In the Québec public school system, a governing board is elected is each school with members consisting of the school principal, teachers, students, parents, and community representatives.
} 
The consultation and information processes worked according to a well-defined structure based on the classroom group and grade representatives. By way of example, student council meetings were structured according to an agenda, which, moreover, was the responsibility of the student council members - and not of the adults who supervised these activities. The statements gathered suggested that the participation in a structure of democratic (i.e., representative) culture at school provided a basis for learning how to express views and make decisions at a range of levels of input. It appeared, therefore, that the voicing of opinions supported these young people's agency:

What gets done at the student council is just a ripple on the surface. [...] For the big changes, it's a bit more the board, where we have a voice with our presidents. [...] But (the important thing is...) letting others come forward with their ideas; I mean, that there's a real exchange of ideas that takes place. (S6)

This democratic participation structure has limitations, but it has the merit of at least providing a forum for debates and conveying the opinions of students to the decision-making bodies. The voicing of opinions fostered horizontal communication which, in return, supported students' agency. At that point, these students learned to consider themselves as legitimate interlocutors who were listened to by the adults at the school - a fundamental lesson in order to become actively engaged in democratic debates.

Quality of the relationship between students and adults at the school. A number of years ago the new principal and her team decided, together with the teachers, to foster a pedagogical relationship that took into consideration the overall development of young people and accounted for their needs. For example, the attentiveness of adults facilitates the passage from primary school to secondary school, a period described by students as a major change in their lives. The students we encountered described how the principal decided to modify the traditional form ${ }^{2}$ associated with high schools, that is "specific rules, standards and evaluation modes, a delimitation of time and space, a more or less democratic mode of operation, more or less egalitarian authority relationships, periods of silence or listening" (Horman, Bader, \& Lapointe, 2008, p. 145), so as to provide students greater relational stability with their teachers and other people having the same grade or age as they:

Primary school is, like, more for kiddies, but at high school, you're left a bit more to look after yourself. You're left, like, you have to look after your things, you have to live your life. In secondary school, you arrive, and, like, I was afraid. What happened when we entered Secondary 1 [grade 7], we had two teachers. We had only two teachers who taught 4 or 5 class subjects each. That meant, we had high school all the same, but a bit less than the other normal ones. [...] What's great is when you come here, the teachers are there to help you. (S4)

The quality of this relationship to adults at the school contributed to a positive school experience. Two characteristics emerged from the students' statements concerning their relationship with the school's adults: engagement and competency. The reciprocity characterizing teachers' and students' engagement appeared to be related to the mutual good feeling generated around a shared passion and a certain disinterestedness on the part of teachers, over and beyond job-related duties:

And, the concert of movie music for students in Secondary 4 and 5 [grades 10 and 11]. Now that's what you call audiovisual. Meaning, they created montages. They (the teachers) take a movie and then divide it up into smaller pieces. Then they project it on wide screen and the students play music over it, and it fits with the tune. The teachers really aren't required to do that, but they do it. (S3)

\footnotetext{
${ }^{2}$ In French, forme scolaire, as defined by Vincent (1994) is referred to as 'grammar of school' in English.
} 
A closer examination of this mutual good feeling and pride shows that the engagement and reciprocity surrounding a common passion are somewhat of a prerequisite for what is genuinely appreciated by young people, namely "the competency that adults make available for the accomplishment of students' projects" (S3). The students acknowledged that the contribution of this adult competency enabled them to achieve outcomes that went beyond their current capacities: "You know, you have the feeling that it's really professional, but it's high school students who are doing it" (S4).

To sum up, the statements presented concerning these three aspects of a school structure and culture of democratic engagement provided evidence that horizontal communication, conducted in an attitude of respect and accompanied by mutual engagement, was conducive to the enactment of a DCEC project.

\section{The Educational and Democratic Character of the DCEC Project}

The statements gathered from students brought out a number of major points to be considered in relation to the type of school culture that facilitated the achievement of the aims of engagement and critical pedagogy associated with DCEC projects. DCEC projects work according to an approach where students chose, in a democratic fashion, a cause that is aimed at improving the living conditions of their community. Within the framework of the present DCEC project, it can be said that the project was selected in a democratic fashion for two reasons. First of all, the project was selected on the basis of a situation that was felt to be unfair by students: "It really created some bad publicity, but more than that, there's, like, half the things weren't true" (S1). And second, this choice emerged through the structures of democratic participation in school life put in place by the principal in order to empower the students and provide them with a cultural capital which was absent in their family environment:

He [name of the recreation technician] spoke to us about it (the DCEC project) before Christmas. And then, after Christmas, there was the fight and the radio school bashing, and then, at that point, we had our meeting to decide what we were going to do, and so we decided to do a project that would change the image of our school. We first thought of this project within the DCEC group [...] then we presented it to the student council, and then we took it to the board. (S1)

Some criticism could be levelled at the DCEC projects for the low number of concrete results (i.e., in terms of services or service structures in the neighbourhood) achieved by students. However, it is important to recall that the aims of this type of project are defined in terms of learning - and not just in terms of practical outcomes. According to the recreation technician, the students made numerous learnings that strengthened their agency, such as developing interpersonal skills, responsibility, and skills in initiating and carrying out a project:

(they learned) how to put together a project, how to start from scratch and arrive at something tangible, to correctly perceive the steps involved in carrying it out, the involvement, the planning, the implementation, the evaluation, seeing what could have been done at the start that would have helped the most. At the next step in implementation, we'd see how it was going to work out.

It could also be suggested that this project offered an opportunity for learning responsible citizenship, considering that, in their capacity as citizens, students proposed a way of reacting to a situation harmful to the community. On the basis of discussions around a problem situation, they identified the issue of the reputation of the school, the neighbourhood, and the young people who inhabit it as one of intergenerational confidence, and they developed a 
strategy in order to counter this problem. This strategy turned into the concrete project to be carried out:

That's what we want to do, the vision [of the school and the neighbourhood], and the intergenerational, too; y'know, seniors often say "Ah! Young people these days, and all that" [...] That's why, like, we decided to target three groups: children, child-care centres and primary schools, and elderly people. (S3)

The way in which the DCEC project was enacted in the school and the lessons that flowed out of the project seem initially to be connected to the conditions offered to students in terms of anchoring the school in the neighbourhood and gaining experience in participating in a democratic culture. This we have illustrated in the previous two sections. These conditions contributed to building a space of legitimacy for voicing opinions and decision making by students: "The ability to do a little bit what we wanted to. 'Cuz imposing a project on young people, I don't know, it doesn't work as well as letting them create their own project" (S4).

This pedagogical approach does not rank among the easiest or most comfortable ones. At the same time, it was what the students most appreciated about the project during implementation - the project stemmed from their concerns and emerged from a decision they had reached following discussion: "We decided everything in that way; everyone was in agreement" (S1). This approach was characterized by flexible supervision and support for students' responsible empowerment:

I also learned to reach out toward others; sometimes it's...the first step is hard, it's a hurdle, but then, you don't have any choice [...] You have to do it; you decided to get involved, and then the project rests on your shoulders a bit. You have to make the first step. Once you've done it, you see it wasn't all that bad. (S7)

Such responsible empowerment appeared to be at the centre of the lessons confronting the students throughout the completion of the DCEC project. They especially required the support of adults during their interactions with other adults when soliciting by phone the collaboration of other partners on their project. This made for a sensitive situation because even as they attempted to improve the image and trust that adults had of and in them, it was this same trust that they were soliciting at the time of the project launch that was a source of problems: "Well, people are a bit sceptical. My feeling is, since it's young people who are organizing it... Our reputation hasn't been built yet, because people (think): Right, a little bunch of whippersnappers who's organizing it..." (S3).

\section{Discussion}

In a context in which the school is firmly anchored in its community and democratic participation in school life is already intense, the DCEC project appeared to trigger learnings in a situation of authenticity as well as a certain emancipation of students - as opposed to confining learning to an exercise in theory. This observation tends to highlight the importance of launching DCEC projects and the like in as intense and well-supported a field of participation as possible (i.e., a space in which students already enjoy legitimacy as social actors), even if it means expanding this field over the course of the project.

By way of contrast, for want of the kind of support that can be fostered by the school culture via a space of legitimate participation, a DCEC project can, instead, become a simulacrum of democratic participation, as when, for example, students are signed up to perform tasks that have been decided on by other actors. It would appear that one of the conditions that contribute to real learnings of the kind targeted by DCEC projects is that projects should 
be proposed by the students themselves. From this perspective, the designing and completion of DCEC projects would benefit from being framed according to the principles of an emergent, critical pedagogy, as well as in school where the principal and other adult leaders act in a transformative way. Otherwise, major discrepancies can occur between the goals of DCEC projects and their transposition into a real process of actualization. In the case of this school's DCEC project, it is just this practical actualization of critical goals of an emergent pedagogy and of transformative leadership that seems to have made the project so interesting.

In this context, the DCEC project indeed appears to channel the students' agency in hopes of correcting a problem situation for themselves and their community. Agency and empowerment imply, in relation to young people, both sensitivity to living conditions and the capacity to adopt responsible behaviours in view of improving these conditions. In this, we draw on Apple (2002), who defined and developed the notions of agency and empowerment in connection with legitimate representatives in the social sphere. The DCEC project of this school did not originate in a desire to improve the community without considering those who make it up. Indeed, it is the students own relationship to their community that is seen as possibly being improved through the transformation of certain living conditions in their community. The central issue is to transform one's own living conditions as well as those of others, and to rectify certain prejudices that are harmful to social ties. This position is consistent with certain principles of critical pedagogy and transformative leadership that advocate for improving the living conditions of social actors, such that by enhancing their identity through civic engagement they are also empowered to unmask certain forms of domination or alienation to which they are subjected.

Projects initiated by students based on their life experience are far from being commonplace in schools. Knowing this, it cannot be expected of young people that they work alone on such projects, nor is it possible to evaluate their success or failure without also taking into account the fact that such successes or failures are dependent on a whole societal dynamic (i.e., community partners who do or do not get involved, the media, parents, other students, teachers, school leaders, and so on). It should also be noted that in the present case, students truly had their work cut out for them, having elected to try and correct a number of received ideas - that permeate many public discourses and that, through such discourses, tend also to be reinforced - that were firmly rooted in the community. This view is in keeping with Kellner (2001) who noted Henry Giroux's sharp criticism of the proliferating portrayals of teenagers as decadent, corrupt individuals who must be controlled and disciplined.

According to the perspective of cultural studies in education that we have adopted in this article, identity is not conceived of according to an essentialist mode, as though constituting something that a person "possesses" according to his or her "nature." We instead hold to the view that in order to structure their identity, individuals refer to cultural practices and social events of concern to them (Barker, 2004). "Within cultural studies," to borrow from Barker (2004), "identities are understood to be discursive-performative. That is, identity is best described as a discursive practice that enacts or produces that which it names" (p. 61). As a result, identity is conceived of as being "plastic and changeable, being specific to particular social and [discursive] conjunctures"(Barker, 2004, p. 61) rather than as a fixed essence. For this reason it is linked not only to current capacities but also to processes of becoming - a becoming that is constantly produced through shifts in descriptions of oneself and one's horizons. With these considerations in mind, it becomes clear how a media-borne discourse can have a major impact on the reputation of a school and on neighbourhood belonging, for the comments of the radio host are considered by the students as an identity discourse that places limitations on their becoming. Such conjunctures have a powerful effect since this type of discourse acquires a credibility owing to the mirroring effect of material 
conditions (e.g., low income and substance abuse situations) and collective commentary, as repeated in the media.

\section{Conclusion}

The make-up of our sample, based as it was on students' voluntary participation, constitutes a limitation of our study since we did not gather the statements of all the students involved in the school's project and we gathered no information from students that were not involved in the DCEC project. As a result, no generalization can be made on the basis of observations presented here and several aspects of this study merit being documented more extensively throughout a broader population. However, enough indications are provided by the statements of the students whom we met to make it possible to place these results in relation to certain aspects of critical pedagogy and transformative leadership. Beyond its concrete, situated character, the project presents similarities with critical pedagogy and transformative leadership on the basis of its objectives of changing living conditions and power relationships between social groups. It deals with an event that was experienced, perceived, and interpreted as unfairness by young people and can thus be associated with the exercise of responsible citizenship.

One of the challenges of citizenship education is the need to revitalize young people's participation in democracy. The goal is a form of democratic participation that should be characterized by the legitimacy of each of the social actors involved and that should seek to establish more egalitarian power relations in contemporary societies - in contrast with a conception of civic education that fails to sufficiently explicate the means by which power relations in society could be modified:

Agency in this view is completely depoliticized and defines politics through a discourse of cynicism that suggests that there are no collective structures or agents to challenge existing relations of power [...] Critical education and democratic politic have become disposable, unnecessary, if not threatening to a society that privileges inequality over justice, profits over social needs, and short term gains over the future. (Giroux, quoted by Pozo, 2004)

How will a person be able to become engaged if he or she does not view him- or herself as a legitimate actor in the community? How will such a view develop if a person has never been recognized as a legitimate actor? Moreover, while legitimacy is a prerequisite for engagement, it is not the only such essential condition, as it also goes hand in hand with hope. According to Giroux (2005), hope is a condition required in order for individuals to consider themselves as social actors: "Hope must be tempered by the complex reality of the times and viewed as a project and a condition for providing a sense of collective agency, opposition, political imagination, and engaged participation" (Giroux, quoted by Pozo, 2004).

The young people whom we met appear to be filled with hopes, be these personal career projects or expectations for their school and those students who will attend it in the future. In order to succeed, community engagement projects must cultivate these movements of hope. Hope does not consist merely in generating fantasies. When associated with critical reflection, hope becomes a way of recognizing the non-determinist character of the present and opens onto spaces of meaning and action having the potential to actualize a direction pursued by citizenship education (Giroux, 2004b).

The experience described in this article has drawn our attention to how the pedagogical and leadership conditions offered by the school and the way DCEC projects are launched and carried out have an impact on the success of such projects. Emergent pedagogy shares with a democratic culture a mode of operations that legitimates those social actors known as students. Whenever students are made partners, in some form or other, of all the steps of a 
DCEC project, their engagement will allow them to enjoy a positive experience of democratic participation, one that supports hope as a vital condition of engagement and responsible citizenship in general.

In short, this project stands out as a mesh of constructions of spaces of meaning and spaces of action. In other words, it embodies not only a capacity to exert influence and to act responsibly, but also an opportunity to share in improving one's own living conditions as well as those of others. That is, after all, what is generally understood by the mission of educational and responsible citizenship, wherein rights and responsibilities go hand in hand.

\section{References}

Apple, M. (2002). Power, meaning and identity. New York: Peter Lang.

Bader, B. (2010, May). Pédagogie critique en éducation relative à l'environnement. Invited paper presentation, Université d'Aix-Marseille.

Barker, C. (2004). The sage dictionary of cultural studies. Thousand Oaks, CA: Sage Publication.

Établissements Verts Bruntland. (2005). Centrale des Syndicats du Québec. Retrieved November 11, 2010, from http://evb.csq.qc.net.

Freire, P. (2004). Pedagogy of indignation. Boulder, CO: Paradigm Publishers.

Giroux, H. A. (1988). Teachers as intellectuals. Toward a critical pedagogy of learning. Granby, MS: Bergin \& Garvey Publishers.

Giroux, H. A. (2004a). The abandoned generation: Democracy beyond the culture of fear. Basingstoke, UK: Palgrave MacMillan.

Giroux, H. A. (2004b). When hope is subversive. Tikkun, 19(6), 38-41.

Giroux, H. A. (2005). Schooling and the struggle for public life: Democracy's promise and education's challenge. Boulder, CO: Paradigm Publishers.

Horman, J., Bader, B., \& Lapointe, C. (2008). Pour une culture scolaire de l'engagement communautaire et citoyen. In R. Deslandes (Dir.), La collaboration de l'école, de la famille et de la communauté à l'apprentissage (pp. 135-150). Cahiers scientifiques de l'ACFAS, 109.

Kellner, D. (2001). Critical pedagogy, cultural studies, and radical democracy at the turn of the millennium: Reflections on the work of Henry Giroux. Cultural Studies-Critical Methodologies, $1(2), 220-239$.

Lapointe, C., Shields, C. M., \& Langlois, L. (2009). Transformative leadership, a possible solution to inequity in education. Unpublished working paper, Faculté des sciences de l'éducation, Université Laval, Québec.

Paillé, P. (1996). De l'analyse qualitative en général et de l'analyse thématique en particulier. Revue pour la Recherche Qualitative, 15, 179-193.

Pouliot, C., Bader, B., \& Therriault, G. (2010). The notion of the relationship to knowledge: A theoretical tool for research in science education. International Journal of Environmental and Science Education, 5(3), 239-264.

Pozo, M. A. (2004). An educator's reflections on the crisis in education and democracy in the US: An interview with Henry A. Giroux, September 25, 2004. First published in Axis of Logic. Retrieved November 11, 2010, from http://dissidentvoice.org/Sept04/Pozo0925.htm

Shields, C. M. (2010). Transformative leadership: Working for equity in diverse contexts. Educational Administration Quarterly, 46(4), 558-589.

Vincent, G. (Ed.). (1994). L'éducation prisonnière de la forme scolaire? Scolarisation et socialisation dans les sociétés industrielles. Lyon, FR: Presses Universitaires de Lyon.

\section{Authors' Note}

Correspondence concerning this article should be addressed to Barbara Bader, Faculté des sciences de l'éducation, Université Laval, Québec, QC, G1K 7P4.

Email: Barbara.bader@fse.ulaval.ca 